\title{
Thermal Analysis and Quality Control of Polyolephines
}

\author{
${ }^{1}$ Lenar N. Shafigullin, ${ }^{2}$ Natalia V. Romanova, ${ }^{3}$ Gulgena D. Shakirova \\ ${ }^{1-3}$ Kazan Federal University \\ Email: misharin_82@mail.ru, Romanova.NV@kamaz.ru,nurlieva@mail.ru
}

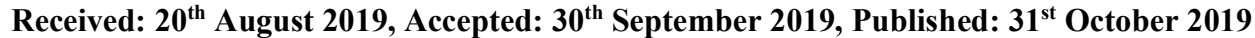

\begin{abstract}
In the work, thermal studies of compositions based on polypropylene were carried out and, depending on the composition of the composition, a comprehensive assessment of the quality of materials of polymer automotive components was carried out, since comprehensive quality control of materials is the confidence that the finished products are of high quality, which is always maintained at the official level.

Comprehensive studies of the quality of the material of automotive components products depending on the content of filler-talc and high-density polyethylene HDPE in the polypropylene composition are proposed, consisting in evaluating the thermophysical parameters of the composition and the effect of the composition on the physicomechanical properties of the finished product.

It was revealed that the samples of the details of various batches differ in the composition of the polymer matrix from the initial required raw material of the PP composition. It was determined that HDPE is present in the PP composition, which can have a negative effect on the quality of finished products according to the required level of physical and mechanical characteristics. Thus, studies using differential scanning calorimetry showed that two minimums are observed in the samples of materials of automotive components products: the first of two minima (endotherm) indicates the melting of polyethylene $\left(130-135{ }^{\circ} \mathrm{C}\right)$, which occurs at a lower temperature, and the second, observed at a higher temperature, corresponds to the melting of polypropylene $\left(165-170{ }^{\circ} \mathrm{C}\right)$. Peak area is a measure of the relative content of components in a material. The calculation of the relative content of polyethylene and polypropylene in all studied samples of the composition details was carried out. It was found that, on average, the relative calculated value of the polyethylene content in the composition varies from 20 to $25 \%$ of the mass, and the relative calculated value of the polypropylene content in the composition is from 74 to $82 \%$ by mass.

It is shown that the lack of quality of the material can be established at the stage of input control. A method for evaluating the composition of the material of products is proposed, which indicates the difference between batches of products of automotive components and can serve as a basis for accepting or rejecting this lot by conducting a sufficiently short-term DSC analysis and calculating the relative content of polyolefins in the composition.
\end{abstract}

Keywords

Polypropylene, Polyethylene, Differential Scanning Calorimetry, Product Quality.

\section{Introduction}

Polyethylene and polypropylene occupy $54 \%$ of the total world production of polymers and are the basis for the production of many composite materials, due to the diversity of their properties, determined by the synthesis of the polymer matrix and the nature of other components that make up the polymer composition [1-10].

In the auto industry from the compositions based on polyolefins, in particular, polypropylene makes the large spectrum of the components of auto-components, for example, such as the silencers of the rotary headlight, casing of air of filters, different tanks, etc

One of the important factors, which determines the success of complex quality control in the production, this is confidence in the fact that the materials possess the high quality, which always remains at the official level. If they take place of the fluctuation of the indices of the properties of the source material, then this forces the processor to continuously regulate the technological process to compensate these fluctuations. So that the articles would be highquality, the obtained by production raw material must answer the specification of the customer, and the indices of his properties must be plotted in the framework of the requirements of production. Some fluctuations of properties are permitted. Thus, for instance, all parties raw material, even relating to the same stamp, and the like nevertheless slightly are differed from each other, even if they are set by the same producer and are obtained in the continuous process.

Many plastics are to the mixture of the materials, which relate to different type polymers, and in this case the parties of such materials they obtain in the reactors of periodic action. Changes in the properties of this production can occur as a result of the fluctuations of the parameters of the process. After several cycles of technological process, in which is accomplished the mixing of initial parties, fluctuation of properties can prove to be not so significant, so as to exceed the limits of the requirements of materials list and to influence the quality of the production, utilized during the processing, so that the batch mixing of source material it contributes to the smoothing of a variation in the properties of the material, supplied for processing into products. The fluctuations of properties can prove to be more significant if raw material comes from different producers since each of them is had special features of the technological process. 
The main problem for the processors of raw material, i.e., the producers of end products - this absence of detailed knowledge relative to the special features of the properties of more than 30 different forms of the processed polymers. Moreover, each such species includes hundreds of different brands. These grades can be pure polymers, and copolymers, mixtures, and alloys of various polymers containing various additives (for example, minerals, carbon black, elastomers, lubricants, processing aids, flame retardants). Any changes in the content of each of these components lead to the appearance of a new brand of material. Such changes are significant concerning the base polymer since a variation in molecular weight leads to a change in viscosity, which, in turn, affects the ease of processing of the material. If the composition of the additives introduced into the polymer is changed to adapt its properties to the requirements of the customer, then this automatically creates the need for additional control and permissible regulation limits.

When the main certification parameters are set for a particular product and selected material, you must have data for the selected batch of material. Firstly, the consumer wants to be sure that in the case in question the selected material is used. Secondly, you can completely trust the manufacturer that he delivers products of appropriate quality. At the input control, thermal analysis methods are usually widely used. This data can be used to verify the correctness of the information provided by the supplier and to verify the identity of batches from the manufacturer.

Thermal analysis methods can indicate the difference between batches and serve as the basis for acceptance or rejection of a given batch of the product by conducting a sufficiently short-term analysis [11].

\section{Methods}

DSC analysis was recorded using a Netzsch DSC 204 F1 Phoenix differential scanning heat flow calorimeter. DSC analysis was carried out in the dynamic heating/cooling mode at a rate of $10^{\circ} \mathrm{C} / \mathrm{min}$ in an argon flow at a speed of $50 \mathrm{~cm}^{3} / \min$.

Thermograms were taken in accordance with GOST R 56724-2015 (ISO 11357-3: 2011). Samples of materials went through the following steps: melting-crystallization-melting. The sample was heated to $200{ }^{\circ} \mathrm{C}$ at a speed of $10 \mathrm{~K} /$ min and cooled at a speed of $10 \mathrm{~K} / \min$ to $50{ }^{\circ} \mathrm{C}$.

The heat of fusion of polyethylene with a crystallinity of $100 \%$ was taken equal to $290 \mathrm{~J} / \mathrm{g}$, and for polypropylene with a crystallinity of $100 \%$ - $198 \mathrm{~J} / \mathrm{g}$ [12].

Thus, the degree of crystallinity of the samples was determined in accordance with the equation:

$\alpha=\left(\Delta \mathrm{H} / \Delta \mathrm{H}_{\mathrm{st}}\right) 100 \%$,

where: $\Delta \mathrm{H}$ is the heat of fusion of this sample according to differential scanning calorimetry;

$\Delta \mathrm{H}_{\mathrm{st}}$ is the heat of fusion of the standard, that is, of the same polymer with a crystallinity of $100 \%$.

Physico-mechanical properties were determined using GOST 4648-2014.

\section{Results and Discussion}

The key parameter, which largely determines the properties and technology for producing filled polymer composite materials, is the concentration of the filler. The concentration of the filler has a major influence on the physicomechanical properties of polymer composites and the technology for processing the starting polymers in them.

Talc is an important reinforcing filler for plastics, in particular, polypropylene. The main stimulus for the use of talc is the improvement of mechanical properties, including an increase in the allowable deformation temperature, rigidity, creep resistance, and shrinkage is also reduced. Additional benefits are associated with the flocculent structure of talc, which increases dimensional stability. Typical talc content in PP is from 10 to $40 \%$ of the mass [13].

At the first stage of comprehensive studies of the quality of the material of automotive components, the content of talc in the polypropylene composition was determined, and its effect on the physicomechanical properties of the finished product was evaluated. It is known that the studied brand of the polypropylene composition is made based on a homo- or copolymer of propylene and may contain from 20 to $29 \%$ of the mass. talc, the following physical and mechanical characteristics are achieved: bending stress of at least $30 \mathrm{MPa}$, Charpy impact strength of the specimen without notch of at least $58 \mathrm{~kJ} / \mathrm{m}^{2}$.

In table. 1 the influence of the content of mineral on the bending stress of the composition of polypropylene is shown.

\begin{tabular}{|l|c|c|c|c|}
\hline Indicator name & \multicolumn{3}{|c|}{ Composition of PP } \\
\hline Content of talc, \%mass & - & 7 & 25 & 29 \\
\hline Bending stress at maximum load, MPa & 21 & 23 & 30 & 32 \\
\hline
\end{tabular}

Table 1: Bending Stress of the Composition of PP

Thus, according to the results of evaluating the content of the mineral filler in the composition of polypropylene, it is possible to forecast physicomechanical the indices of the finished article. Thus, with the content of talc in the composition of polypropylene, it is less than $20 \%$ mass. is not reached the required level of index bending stress not less than $30 \mathrm{MPa}$. 
The basic task of the user of the finished articles of auto-components, prepared from the polymeric materials, is the need for analyzing the correspondence of the material used to the declared type of polymer. The only way to obtaining correct results consists of the use of thermal methods of analysis, in particular, the differential scanning calorimetry (DSK).

It is possible to estimate the curves DSK, what curves correspond to qualitative or poor quality models. On the curves DSK, measured with a study of thermoplastics, it is possible to determine the regions of melting and melting point of each component, which forms part of the composite, and its relative content. Partially crystallizing polyolefins is determined by the degree of crystallinity, and also the recommended rate of cooling, which will allow reaching maximum crystallinity and thus the greatest strength of the article. Method DSK also makes it possible to establish the correct content of the base polymers [14, 15].

In Fig. 1 are given the DSK- curves, which relate to the granules of the required raw material and material finished of the articles of different parties, which must be prepared based on this raw material.

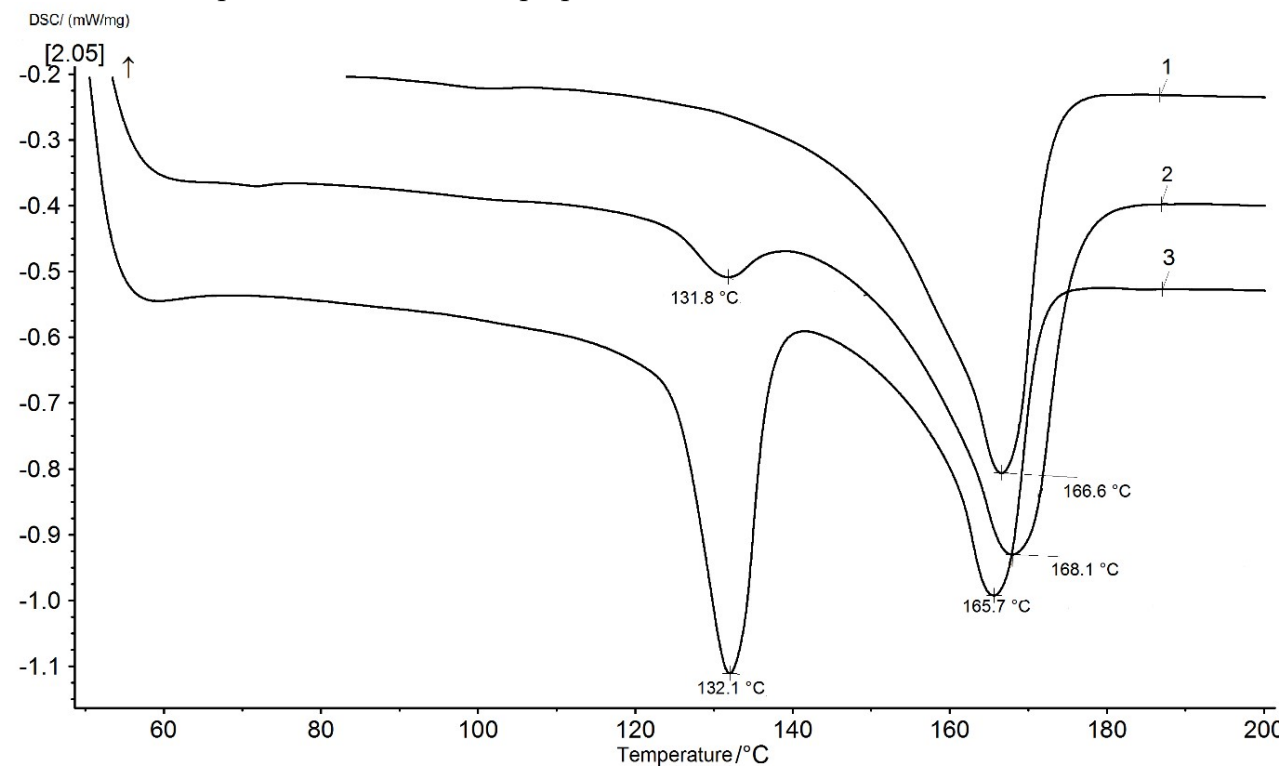

Figure 1: DSC-curves of the Composition PP (to Granule) (1), of the Material of Different Batches of Products: Sample 1 (2) and 2 (3)

Analysis Fig. 1 it showed that on the DSK-curved models of the material of finished articles are observed two minimums, the first of two minimums (endotherm) testifies about melting of polyethylene, proceeding at a lower temperature, and the second, observed at a higher temperature, it answers melting polypropylene. Peak area is a measure of the relative content of components in a material. Therefore, at the next stage, the analysis of DSC curves was carried out, based on which the relative content of PE and PP in the composition of the studied samples of the details of different batches was calculated, while the sample number characterizes the batch number.

The study of the melting process of the samples was carried out using DSC. DSC data obtained from melting endotherms and exotherms of crystallization of PP are presented in table 2 . When calculating the degree of crystallinity, the specific heat of fusion for $100 \%$ crystalline PP is $-198 \mathrm{~J} / \mathrm{g}, \mathrm{PE}-290 \mathrm{~J} / \mathrm{g}$ [12].

\begin{tabular}{|c|c|c|c|c|c|c|c|c|}
\hline № heating & $\begin{array}{l}\mathrm{T}_{\max . m e l} \\
{ }_{\mathrm{t}} \mathrm{PE},{ }^{\circ} \\
\mathrm{C}\end{array}$ & $\begin{array}{l}\Delta \mathrm{H}_{\text {melt }} \\
\mathrm{PE}, \\
\mathrm{J} / \mathrm{g}\end{array}$ & $\begin{array}{l}\mathrm{T}_{\text {max.melt }} \\
\mathrm{PP},{ }^{\circ} \mathrm{C}\end{array}$ & $\begin{array}{l}\Delta \mathrm{H}_{\text {melt }} \\
\mathrm{PE} \\
\mathrm{J} / \mathrm{g} \\
\end{array}$ & $\begin{array}{l}\mathrm{T}_{\text {maxcr }} \\
\mathrm{PP},{ }^{\circ} \mathrm{C}\end{array}$ & $\begin{array}{l}\text { Degree of } \\
\text { crystallinity, } \\
\%\end{array}$ & $\begin{array}{l}\text { Calculated } \\
\text { content PE, \%* }\end{array}$ & $\begin{array}{l}\text { Calculated } \\
\text { content PP, \% } \\
* *\end{array}$ \\
\hline \multicolumn{9}{|c|}{ Composition of PP (granule) } \\
\hline 1 & & & 170.9 & 53.3 & 122.5 & 26.9 & & \\
\hline 2 & & & 166.6 & 60.5 & 122.7 & 30.6 & & \\
\hline 3 & & & 166.3 & 61.0 & & 30.8 & & \\
\hline \multicolumn{9}{|c|}{ PEHD (granule) } \\
\hline 1 & 135.5 & 140.0 & & & & 48.3 & & \\
\hline 2 & 134.3 & 152.3 & & & & 52.5 & & \\
\hline 3 & 134.1 & 151.0 & & & & 52.0 & & \\
\hline \multicolumn{9}{|c|}{ Sample } \\
\hline 1 & 131.3 & 3.5 & 170.2 & 46.6 & 120.9 & & 2.5 & \\
\hline 2 & 131.8 & 2.7 & 168.1 & 48.3 & 120.7 & & 1.8 & \\
\hline
\end{tabular}




\begin{tabular}{|c|c|c|c|c|c|c|c|}
\hline & & & & & & & \\
\hline 3 & 131.0 & 2.8 & 167.8 & 48.7 & & 1.8 & \\
\hline \multicolumn{8}{|c|}{ Sample 2} \\
\hline 1 & 133.6 & 31.7 & 170.9 & 37.0 & & 22.6 & 75.5 \\
\hline 2 & 132.1 & 32.8 & 165.7 & 36.4 & & 21.7 & 74.3 \\
\hline 3 & 131.9 & 32.8 & 165.4 & 36.4 & & 21.7 & 74.3 \\
\hline \multicolumn{8}{|c|}{ Sample 3} \\
\hline 1 & 133.1 & 34.8 & 168.7 & 40.4 & 121.7 & 24.8 & 82.4 \\
\hline 2 & 132.0 & 34.4 & 166.0 & 39.2 & 121.3 & 22.6 & 80.0 \\
\hline 3 & 131.9 & 34.4 & 165.9 & 39.9 & & 22.6 & 81.4 \\
\hline \multicolumn{8}{|c|}{ Sample 4} \\
\hline 1 & 134.3 & 31.1 & 170.3 & 38.1 & 120.8 & 22.2 & 77.7 \\
\hline 2 & 133.2 & 31.3 & 167.3 & 36.1 & 120.8 & 20.5 & 73.6 \\
\hline \multicolumn{8}{|c|}{ Sample 5} \\
\hline 1 & 130.1 & 29.1 & 170.5 & 37.7 & 122.0 & 20.7 & 76.9 \\
\hline 2 & 131.2 & 29.5 & 166.0 & 39.9 & 122.0 & 19.5 & 81.4 \\
\hline
\end{tabular}

Table 2: Thermophysical Properties

* When calculating the PE content, the specific heat of fusion of the sample "raw materials in the form of granules PEND" for the 1st heating $-140 \mathrm{~J} / \mathrm{g}, 2$ and 3-151 J / g was taken.

** When calculating the PP content, the specific heat of the fusion of the PP "sample 1 part" was taken - $49 \mathrm{~J} / \mathrm{g}$.

The 1st melting enthalpy is the melting enthalpy of the starting material. 2nd melting enthalpy is the melting enthalpy of molten and newly crystallized material. Crystallization and melting occur under identical conditions.

The enthalpy of the 1st and 2nd melting of the base polymer pp, which forms part of the source material of composition pp, have essential differences in all samples under investigation both the initial granules and in the finished products. The enthalpy of the 2 nd and 3rd melting of all samples is almost the same, which indicates the same thermal background of the samples.

Previously, the thermal parameters of the PP composition were evaluated, as well as used as an additional component of the PE.

It is known that polyolefins with high tact crystallize only partially. he degree of crystallization depends on the structure of the material, but also on the conditions of crystallization, especially on the cooling rate and the applied mechanical stress [16]. Analysis of the degree of crystallinity of the studied raw materials PP and PE showed that the degree of crystallinity of PE is $52 \%$, and the composition of PP - 30\% (table. 2). Analysis of the melting endotherms of PP and PE raw materials in the form of granules showed an increase in crystallinity of $4 \%$ for all types of raw materials.

Thermal studies of the granules of the feedstock-PP composition necessary for the manufacture of the part showed that the temperature and enthalpy of melting of the 1 st heating and 2 nd heating have significant differences. So, the melting temperature of the first heating is $170.9^{\circ} \mathrm{C}$, and the second is $4.6^{\circ} \mathrm{C}$ lower. Studies of the finished product, sample 1 of the part, that is, the feedstock after processing, showed a decrease in the melting temperature from 170.2 ${ }^{\circ} \mathrm{C}$ to $167.8^{\circ} \mathrm{C}$, while the melting enthalpy was $48.5 \mathrm{~J} / \mathrm{g}$, which is lower than the melting enthalpy of the feedstock by $12.5 \mathrm{~J} / \mathrm{g}$. Consequently, processing conditions affect the enthalpy of melting of polypropylene. Therefore, to calculate the relative polypropylene content in the composition, the value of the enthalpy of melting, which is characteristic for sample 1 of the part $\left(\Delta \mathrm{H}_{\mathrm{PP}}\right)$, was adopted.

Thus, the relative content of polypropylene in the composition of the samples of the part was determined by the equation:

$\mathrm{PP}$ content $=\left(\Delta \mathrm{H} / \Delta \mathrm{H}_{\mathrm{PP}}\right) * 100 \%$,

where: $\Delta \mathrm{H}$ is the heat of fusion of this sample according to differential scanning calorimetry;

In almost all investigated samples of the PP composition, polyethylene impurities were found. An analysis of the DSC curves of pure PE in the form of granules showed that the melting temperature remains almost unchanged during the $1 \mathrm{st}$ and subsequent heating processes and is approximately $134^{\circ} \mathrm{C}$, while the melting enthalpy of the 1 st heating is $140 \mathrm{~J} / \mathrm{g}$, and that of the $2 \mathrm{nd}$ and $3 \mathrm{rd}$ heat up $11 \mathrm{~J} / \mathrm{g}$.

Thus, the relative content of polypropylene in the composition of the samples of the part was determined by the equation:

$\mathrm{PE}$ content $=\left(\Delta \mathrm{H} / \Delta \mathrm{H}_{\mathrm{PE}}\right) * 100 \%$,

where: $\Delta \mathrm{H}$ is the heat of fusion of this sample according to differential scanning calorimetry;

$\Delta \mathrm{H}_{\mathrm{PE}}$ is the heat of fusion of the 1 st or 2 nd heating of pure PE in the form of HDPE granules.

Using the above formulas, we calculated the relative content of PE and PP in all the studied samples of the composition details and calculated data are presented in table 2. It was found that, on average, the relative calculated 
value of the polyethylene content in the composition varies from 20 to $25 \%$ of the mass, and the relative calculated value of the polypropylene content in the composition is from 74 to $82 \%$ by mass.

Table analysis 2 showed that the melting endotherms of the studied samples of 2-5 parts change almost identically. So, on the 1 st melting of the PP, a low-temperature shoulder appears (in the region of $162-168^{\circ} \mathrm{C}$ ). The repeated melting of the studied samples of 2-5 parts after recrystallization leads to the disappearance of the low-temperature shoulder of the PP. At the same time, in samples, 2-5, the melting temperature decreases by $2-4{ }^{\circ} \mathrm{C}$, and the magnitude of the melting enthalpy remains practically unchanged.

The reason for the appearance of the low-temperature shoulder on the DSC curve of the samples is the folding of the interlamellar passages. The smallest degree of coagulation during the thawing of their mobility is characteristic of crystallite surfaces. A decrease in the heat of the fusion of the PP of the part samples indicates partial amorphization of the polymer [17].

For PE, the melting temperature and enthalpy have no significant differences. Thus, the melting point of PE in samples $2-4$ is $132-133^{\circ} \mathrm{C}$, which is characteristic of low-pressure polyethylene (LPP).

It was revealed that the samples of the details of various batches differ in the composition of the polymer matrix from the initial required raw material of the PP composition. It is determined that in the composition of the PP is present from 20 to $25 \%$ of the mass. It was determined that HDPE is present in the PP composition, which can have a negative effect on the quality of finished products according to the required level of physical and mechanical characteristics.

The use of DSC analysis is illustrated in Fig. 1 and Table 2, which compares the curves related to the quality batch (curves 1 and 2) in comparison with the batch in which the polypropylene content is insufficient. This can lead to certain problems when using the final product. As can be seen from table 3 when using the finished product with the addition of polyethylene leads to a decrease in bending stress. So, sample 2 of the part is characterized by bending stress of $20 \mathrm{MPa}$ with a normalized rate of at least $30 \mathrm{MPa}$ for the required PP composition.

\begin{tabular}{|l|c|c|c|}
\hline Indicator name & Norm of the composition of PP & Sample1 & Sample 2 \\
\hline Bending stress at maximum load, $\mathrm{MPa}$ & 30 & 30 & 20 \\
\hline
\end{tabular}

Table 3: Bending Stress of Different Batches of Products

Thus, with correctly conducted tests, a lack of quality of the material can be established at the stage of input control. A method for evaluating the composition of the material of products is proposed, which indicates the difference between batches of products of automotive components and can serve as a basis for accepting or rejecting this lot by conducting a sufficiently short-term DSC analysis and calculating the relative content of polyolefins in the composition.

\section{Summary}

1. Thermal studies of base polyolefins in polypropylene compositions were carried out and the quality of automotive components materials was evaluated depending on the composition.

2. Thus, according to the results of evaluating the content of the mineral filler in the composition of polypropylene, it is possible to forecast physicomechanical the indices of the finished product. Thus, with the content of talc in the composition of polypropylene, it is less than $20 \%$ mass. is not reached the required level of index bending stress - not less than $30 \mathrm{MPa}$.

3. According to the DSC curves, which samples of the lots of finished products were evaluated, the parts based on the PP composition correspond to high-quality or low-quality samples.

4. Formulas for calculating the relative content of HDPE and PP in various batches of parts are proposed.

5. It was revealed that the samples of the details of various batches differ in the composition of the polymer matrix from the initial required raw material of the PP composition. It is determined that the composition of the PP is present from 20 to $25 \%$ of the mass. HDPE. It was determined that HDPE is present in the PP composition, which can hurt the quality of finished products according to the required level of physical and mechanical characteristics.

\section{Conclusions}

It is shown that the lack of quality of the material can be established at the stage of input control. A method for evaluating the composition of the material of products is proposed, which indicates the difference between batches of products of automotive components and can serve as a basis for accepting or rejecting this lot by conducting a sufficiently short-term DSC analysis and calculating the relative content of polyolefins in the composition.

\section{Acknowledgments}

The work is performed according to the Russian Government Program of Competitive Growth of Kazan Federal University. Laboratory of non-metallic materials Technological center of Public joint-stock company KAMAZ. 


\section{References}

[1] N.V. Romanova , T.M. Kokina, G.R. Shafigullina, A.R. Ibragimov, L.N. Shafigullin. Thermal studies of polymeric foams, used in engineering // Helix, 2017 .-- Vol. 8 (1). - pp. 2244 - 2248

[2] A. Siriruk, Jack Y. Weitsman, D. Penumadu. Polymeric foams and sandwich composites: material properties, environmental effects, and shear-lag modeling // composites science and technology, 2009. - Vol.69. № 6, pp. 814-820.

[3] N.R. Neng, M.L. Pinto, J. Pires., J.M.F. Nogueira, P.M. Marcos. Development, optimization, and application of polyurethane foams as new polymeric phases for stir bar sorptive extraction // Journal of chromatography A., 2007 - Vol. 1171. № 2, pp. 8-14.

[4] L.N. Shafigullin, A.A. Bobrishev, V.T. Erofeev, A.A. Treshchev, V.T. Erofeev, A.N. Shafigullina. Development of the recommendations on the selection of glass-fiber reinforced polyurethanes for vehicle parts. // International Journal of Applied Engineering Research, Volume 10, Issue 23, 2015, - pp. 4375843762.

[5] Zharin DE, Yurasov SY, Gumerov MI, Shafigullin, LN, Optimal machining of loosely filled polymer composites // Russian Engineering Research, 2010. - Vol. 29, No. 10 - pp. 1007-1009.

[6] N.V. Timoshenko, V.V. Kireev, S.N. Filatov, I.V. Terekhov. The influence of copolymerization conditions of acrylic monomers on the composition and properties of copolymers. Advances in Chemistry and Chemical Technology. Vol. XXIV. 2010. № 2 (107). pp. 90-94.

[7] Yu.D. Semchikov. High Molecular Weight Species. M.: Publishing center "Academy", 2005, 368 pages.

[8] V.V. Kireev. High Molecular Weight Species. M .: Higher School, 1992, 512 pages.

[9] V.N. Kuleznev, V.A. Shershnev. Chemistry and physics of polymers. M.: Kolos, 2007, 367 pages.

[10] V.V. Korshak. The technology of plastics. M .: Chemistry, 1985, 560 pages.

[11] M. J. Gordon injection molding quality management. - SPb. Scientific foundations and technologies, 2012, 824 pages.

[12] Erwin Kaisersberger, Heins Mohler DSC on polymeric Materials NETZSCH Annual for Science and Industry Volume 1. 1991

[13] Functional Fillers for Plastics. / Ed. M. Xanthos. Translation from English under the editorship of V.N. Kulezneva. - SPb .: Scientific foundations and technologies, 2010, 462 pages.

[14] I.F. Gumerov, L.N. Shafigullin, N.V. Romanova, A.T. Gabrakhmanov, D.R. Sarimov. Thermal properties of polypropylene and polyethylene (PP / LDPE) mixtures [thermal properties of polypropylene and polyethylene (PP / LDPE) mixtures]. Materials of the international scientific and technical conference "Innovative engineering technologies, equipment, and materials - 2017". Part 1. Section 1 "high-Performance materials, technologies and equipment in mechanical engineering" [Proc. Int. Sci. and Tech. Conf. "Innovative machine-building technologies, equipment, and materials - 2017". Part 1. Section 1. Highperformance materials, technologies, and equipment in the machine-building industry]. Kazan, 2017, pp. 5760.

[15] Natalia Vladimirovna ROMANOVA, Lenar Nurgaleevich SHAFIGULLIN, Azat Talgatovich GABRAKHMANOV, Damir Ramilevich SARIMOV, Andrei Mikhailovich SOTNIKOV Thermal Properties of Polypropelene /Low-Density Polyethelene (PP / LDPE) Blends Astra Salven. Review of History and Culture Supplement No 2/2017 pp. 387-395

[16] J.L. White, D.D. Choi. Polyethylene, polypropylene and other polyolefins/trans. from English Edited by E.S. Tsobkallo-SPb .: Profession, 2006, 256 pages.

[17] D.Yu. Shitov. Development of nano modified polyolefins [Text]: author. dis. for a job. scientist step. Cand. tech. Sciences: 05.17.06 / Russian Chemical-Technological University named after D. I. Mendeleev. Moscow, 2015, 16 pages. 